\title{
The Importance of Multilocus Sequence Typing: Cautionary Tales from the Bacterium Xylella fastidiosa
}

\author{
L. Nunney, S. Elfekih, and R. Stouthamer
}

First and second authors: Department of Biology, University of California, Riverside 92521; and third author: Department of Entomology, University of California, Riverside 92521.

Accepted for publication 4 January 2012.

\section{ABSTRACT}

Nunney, L., Elfekih, S., and Stouthamer, R. 2012. The importance of multilocus sequence typing: Cautionary tales from the bacterium Xylella fastidiosa. Phytopathology 102:456-460.

\begin{abstract}
Microbial identification methods have evolved rapidly over the last few decades. One such method is multilocus sequence typing (MLST). MLST is a powerful tool for understanding the evolutionary dynamics of pathogens and to gain insight into their genetic diversity. We illustrate the importance of accurate typing by reporting on three problems that have arisen in the study of a single bacterial species, the plant pathogen Xylella fastidiosa. Two of these were particularly serious since they concerned contamination of important research material that has had detrimental consequences for Xylella research: the contamination of DNA used in the
\end{abstract}

sequencing of an $X$. fastidiosa genome (Ann-1) with DNA from another $X$. fastidiosa strain, and the unrecognized mislabeling of a strain (Temecula1) distributed from a culture collection (ATCC). We advocate the routine use of MLST to define strains maintained in culture collections and emphasize the importance of confirming the purity of DNA submitted for sequencing. We also present a third example that illustrates the value of MLST in guiding the choice of taxonomic types. Beyond these situations, there is a strong case for MLST whenever an isolate is used experimentally, especially where genotypic differences are suspected to influence the outcome.

Additional keywords: culture collection, diagnosis, phylogeny, taxonomy.
The ability to easily and accurately identify bacterial isolates is fundamental to understanding the epidemiological dynamics and evolution of bacterial pathogens. Numerous serological techniques and genotyping approaches have been used for the detection, diagnosis, and characterization of bacteria (15). In each case, the goal has been to distinguish types based on some form of characteristic fingerprint. But, in general, these approaches are designed to detect a specific set of variants and can fail to detect novelty resulting from new introductions or new recombination events.

To minimize this problem, Maiden et al. (17) introduced multilocus sequence typing (MLST), a typing methodology based on sequencing a short $(<1 \mathrm{~kb})$ region of each of several (usually seven) housekeeping genes. The alleles found at each gene are numbered arbitrarily (usually in the order in which they are found), so that each isolate is represented by the seven numbers corresponding to the alleles at each of the seven genes. Each unique combination of alleles is called a sequence type (ST), and each sequence type is uniquely numbered. Thus, a given strain can be represented by its ST number, which defines seven genespecific allele numbers, each of which in turn defines a particular DNA sequence.

The advantages of this simple but powerful typing method are widely recognized (16) and have resulted in its rapid acceptance, especially for typing human pathogens (the original paper has now been cited in more than 1,200 articles). While acceptance of the method for typing plant-pathogenic bacteria has been slower, a growing number of MLST schemes have now been developed including Pseudomonas syringae (21), Xylella fastidiosa $(22,30)$, fruit tree phytoplasmas (10), Ralstonia solanacearum (7), Xantho-

Corresponding author: L. Nunney: E-mail address: leonard.nunney@ucr.edu

http://dx.doi.org/10.1094/PHYTO-10-11-0298

(c) 2012 The American Phytopathological Society monas spp. (29), and Acidovorax citrulli (13), some of which have been integrated into the PAMDB (Plant Associated and Environmental Microbes Database) website (1).

In addition to the value of MLST in tracking the relationships among isolates from the field, typing helps to ensure that cultures used in research are genetically defined and uncontaminated. We propose that MLST should be routine, but here we emphasize that typing is particularly important in three situations: the final preparation of DNA for genomic sequencing; deposition of isolates in culture collections; and in defining taxonomic types. We illustrate each of these situations with a problem that has arisen in research on the plant-pathogenic bacterium Xylella fastidiosa.

$X$. fastidiosa is a gram-negative, xylem-limited bacterium that infects many plant species, causing scorch and dwarfing diseases. It is transmitted between plant hosts by xylem feeding insects such as leafhoppers. Four subspecies of $X$. fastidiosa have been identified $(23,26)$, each showing a high degree of host specificity. $X$. fastidiosa subspecies fastidiosa is responsible for Pierce's disease of grapevine (6), but also causes disease in almond, alfalfa, and, in Central America, coffee (19). Subsp. sandyi is largely restricted to oleander (30), and subsp. multiplex (like subsp. fastidiosa) causes disease in almond, but also causes disease in other related fruit trees including plum, peach, and apricot. In addition, it infects a range of native trees, including oak and sweetgum $(14,23,26)$. The fourth subspecies, subsp. pauca, is found only in South America. It is considered a major threat to the U.S. citrus industry (and as a result is listed as a Select Agent) and causes disease in coffee as well as citrus (19).

The subdivision of $X$. fastidiosa into four subspecies, three of which are found in the United States, and all of which differ in their host range, makes typing (minimally to subspecies) of isolates used in research very important. Multilocus typing is essential for this purpose because recombination among the subspecies has been detected $(19,22,30)$. Such recombination means that no single gene can provide reliable identification, since some alleles 
characteristic of one subspecies can be found in a genome that is predominantly another subspecies. Furthermore, identification to subspecies is only a first step. Isolates of the same subspecies can differ in their host range; for example, the South American subspecies $X$. fastidiosa subsp. pauca infects two economically important crops, coffee and citrus, but the two forms appear to be almost completely specialized to their own plant host (2). Thus, the routine MLST definition of isolates used in experimental work helps to understand the role of genetic differences among isolates in driving differing patterns of pathogenicity. In the absence of typing, problems arise. Using $X$. fastidios $a$ as an example, there is substantial literature documenting the ability of an isolate from one plant host to grow or not grow in other plant species. Unfortunately, not knowing anything about the genotype of that isolate severely restricts the usefulness of the experimental results. In order to begin to eliminate this problem, we have typed more than 250 isolates from the United States, including 85 isolates of the Pierce's disease causing subsp. fastidiosa, and 21 isolates of subsp. sandyi (30). Publication of the results on subsp. multiplex will soon follow (L. Nunney, D. Vickerman, R. E. Bromley, S. Russell, J. Hartman, L. Morano, and R. Stouthamer, unpublished data). The published MLST data are available at http://pubmlst.org/xfastidiosa.

The contaminated Ann-1 genome. The 9a5c strain of $X$. fastidiosa subsp. pauca (a citrus isolate) was the first plant-pathogenic bacterium to be fully sequenced (27). Since that time, additional genome sequences have been completed: three of $X$. fastidiosa subsp. fastidiosa: Temecula1 (27), M23 (9), and GilBec514 (25); and one of X. fastidiosa subsp. multiplex: M12 (9). However, in addition to these six genomes, two of the early draft genomes have not been completed, Dixon (X. fastidiosa subsp. multiplex) and Ann-1 (X. fastidiosa subsp. sandyi), and one additional draft of subsp. fastidiosa has recently been released (EB92-1 [31]). Completion of draft X. fastidiosa genomes can be difficult because of the presence of large duplications; however, the Ann-1 sequence suffers from a much more serious problem. It contains sequence from two different genomes.

The two draft genomes Ann-1 and Dixon were released in 2002 (4). Our independent MLST of these two strains showed that they were genetically distinct with a non-overlapping set of alleles and confirmed that they represented different subspecies (22; Table 1). However, our BLAST searches of the Ann-1 draft genome raised concerns. We consistently found two matches to our MLST gene sequences (30), whereas the Dixon draft genome showed single matches (Table 2). Examination of each pair of gene copies in the Ann-1 draft showed that one copy was identical to the sequence that we obtained from our typing of the Ann-1 strain (30) and the other was identical to the equivalent sequences from the M12 and Dixon genomes (both $X$. fastidiosa subsp. multiplex), with the minor exception that the second $c y s G$ sequence was identical only to Dixon (which differs from M12 by a single snp). These findings showed that the Ann-1 DNA used for sequencing was contaminated with DNA from a strain of $X$. fastidiosa subsp. multiplex. This view is supported by the results of the Joint Genome Institute's reevaluation of the genome data in 2007: while the original 2002 entry in GenBank (NC_002722) listed an estimated sequence length of 2,674,522 bp, updated in 2005 (NZ_AAAM02000000) to 2,622,328 bp, the most recent 2010 version (NZ_AAAM00000000) has an estimated length of $5,115,342 \mathrm{bp}$, i.e., double the length expected in an $X$. fastidiosa genome (Table 2).

The possibility that this subspecies (or even just this isolate) had a duplicated genome was excluded by our MLST typing of Ann-1 and of 19 other X. fastidiosa subsp. sandyi isolates of identical sequence type (30). In all cases, only one copy of each gene was amplified (even though the primer sites were conserved across the two copies in the draft genome). A copy identical to the Dixon sequence was never amplified.

In collaboration with the Los Alamos National Lab, we are now resequencing Ann-1 so that an accurate genome of $X$. fastidiosa

TABLE 1. Multilocus sequence typing (MLST) sequence types for the different Xylella fastidiosa isolates belonging to different subspecies ${ }^{\mathrm{a}}$

\begin{tabular}{|c|c|c|c|c|c|c|c|c|c|c|}
\hline \multirow[b]{2}{*}{ Alias } & \multirow[b]{2}{*}{ Strain/type } & \multicolumn{7}{|c|}{ MLST loci } & \multirow[b]{2}{*}{ Subspecies } & \multirow[b]{2}{*}{ ST } \\
\hline & & leuA & petC & lacF & cys $G$ & holC & пиоL & $g l T$ & & \\
\hline OLS0002 & Ann-1 & 2 & 2 & 2 & 2 & 2 & 2 & 2 & sandyi & 5 \\
\hline ALS0003 & Dixon & $\underline{3}$ & $\underline{3}$ & $\underline{3}$ & $\underline{3}$ & $\underline{3}$ & $\underline{3}$ & $\underline{3}$ & multiplex & 6 \\
\hline PD0001 & Temecula1 & 1 & 1 & 1 & 1 & 1 & 1 & 1 & fastidiosa & 1 \\
\hline ATCC 700964 & Mistaken for Temecula1 & $\underline{6}$ & $\underline{3}$ & $\underline{5}$ & 6 & 7 & $\underline{3}$ & $\underline{7}$ & multiplex & 27 \\
\hline PD0157 & Type subsp. fastidiosa & 1 & $\overline{1}$ & 4 & 1 & 1 & $\overline{1}$ & 1 & fastidiosa & 2 \\
\hline
\end{tabular}

${ }^{a}$ The allele numbers are arbitrary (similar numbers do not represent sequence similarity). Underlined allele numbers are typically found in the subspecies multiplex. "Alias" indicates the strain designation used in our culture collection, while "Strain/type" indicates the original strain name or other information. ST defines the sequence type designation for each strain.

TABLE 2. Comparison of the draft genomic sequence of the Xylella fastidiosa strains Ann-1 and Dixon showing contamination of the Ann-1 sequence ${ }^{\mathrm{a}}$

\begin{tabular}{|c|c|c|c|}
\hline Type culture & \multicolumn{2}{|c|}{ Ann-1 } & Dixon \\
\hline Genome size (bp) & \multicolumn{2}{|c|}{$5,115,342$} & $2,622,328$ \\
\hline Number of protein coding genes & \multicolumn{2}{|c|}{4,660} & 2,358 \\
\hline Number of contigs & \multicolumn{2}{|c|}{219} & 32 \\
\hline MLST loci & Sandyi type & Multiplex type & Multiplex type \\
\hline leuA & $\mathrm{Ctg} 220$ & $\mathrm{Ctg} 257$ & $\mathrm{Ctg} 89$ \\
\hline petC & $\mathrm{Ctg} 256$ & Ctg 166 & Ctg 81 \\
\hline malF & Ctg 147 & $\mathrm{Ctg} 261$ & Ctg 85 \\
\hline пиоц & $\mathrm{Ctg} 266^{\mathrm{b}}$ & $\mathrm{Ctg} 266^{\mathrm{b}}$ & Ctg 90 \\
\hline gltT & $\mathrm{Ctg} 261$ & Ctg 236 & Ctg 92 \\
\hline
\end{tabular}

${ }^{a}$ Location of the gene regions used in multilocus sequence typing (MLST) was established by BLAST analysis of the draft contigs. Genome size and gene number data from the JGI Integrated Microbial Genomics portal (img.jgi.doe.gov).

b Two copies at different locations on the same contig. 
subsp. sandyi will be available to researchers. However, the message of this example is an obvious one. After growing a culture for genomic sequencing (not a trivial task given a slow growing bacterium such as $X$. fastidiosa), the possibility of contamination should be excluded by retyping the DNA. The consequences of not doing this are clearly illustrated in this example. Unknown to the researchers involved, the conclusions of a number of timeconsuming comparative genomic analyses were based in part on erroneous data $(3,11,12)$.

After the release of the Ann-1 genome, its contamination could have been detected in many ways, and the fact that it was detected as a result of MLST is not our main issue. Instead our point is that MLST of the DNA being prepared for sequencing would have revealed the contamination before any effort was wasted on the sequencing, the bioinformatics, and all of the subsequent analyses. It is probable that slow growing microorganisms such $X$. fastidiosa are particularly prone to this kind of contamination.

ATCC 700964 Temecula1 was not Temecula1. Culture collections, such as the American Type Culture Collection (ATCC), are an essential feature of microbial research. They allow researchers to work with defined isolates and so facilitate both confirmation of previous results and the ability to build on them. Serious problems arise if a culture in the collection is incorrectly labeled, either due to submission of the incorrect isolate or subsequent contamination.

This scenario is not an abstraction. A case that created problems in at least three research groups studying $X$. fastidiosa has come to our attention involving the Temeculal isolate. The genome of the Temecula1 was sequenced in 2003 (27) and has been a major resource for scientists studying Pierce's disease. The Temecula1 isolate has been used in a number of experimental studies (20), and was available from ATCC under the accession number 700964. Unfortunately, when we typed the ATCC culture for a colleague, it proved genetically to be a very different isolate, grouping with $X$. fastidiosa subsp. multiplex (Table 1). We have identified this sequence type (ST27) from almond and plum, but never from grape (unpublished data). Clearly, any research using this culture based on the assumption that it is Temecula1 is problematic.

ATCC has now removed the Temecula1 description from culture 700964; however, it is unknown how many researchers may have previously purchased this culture, or received the culture from colleagues who purchased it. A Google Scholar search with the settings "Articles and Patents," "anytime" and "include references" on 26 October 2011 with the keyword ATCC 700964 returned 44 references, and at least 18 of these used cultures identified by this ATCC number. The best protection against this problem is to incorporate the MLST sequence type into the description of an isolate so that it can easily be checked. To this end, we propose that culture collections adopt MLST for a given taxon as soon as its protocol becomes accepted in the research community, and that, following such adoption, the typing of isolates should be part of the submission procedure. Preexisting isolates already part of the collection could be rapidly typed if DNA samples were provided (free of charge) to appropriate labs, and if specialist journals would consider publishing significant updating efforts in the form of a research note.

Temecula1 is an important research culture because it was the first genome of subsp. fastidiosa to be sequenced. Although in this case the wrong isolate was present in ATCC, we applaud the principle that a culture of each sequenced genome be deposited in an appropriate collection. To date, none of the fully sequenced isolates of $X$. fastidiosa are available from ATCC, although we understand that GilBec514 is in the process of being deposited (L. Morano, personal communication).

Defining taxonomic types. The choice of taxonomic types is based on a range of criteria; however, MLST can be valuable as an additional guide in this process. We again use $X$. fastidiosa to illustrate this point; however in this example we are not criticizing choices made, but simply point out that when MLST is available the choice of a taxonomic type may be influenced, either by reinforcing the choice that would otherwise be made or by suggesting that some other strain may be more appropriate.

Of the four defined subspecies of $X$. fastidiosa only one, $X$. fastidiosa subsp. sandyi, was proposed after MLST data became available (26). The remaining three were defined from the DNA hybridization work of Schaad et al. (23); however, MLST provided very strong support for these subspecific divisions. Based on extensive typing, it is evident that there is no allelic overlap between the subspecies, and phylogenetic approaches based on MLST sequence data yield $100 \%$ bootstrap support for these taxa $(19,22,26,30)$.

The types chosen by Schaad et al. (23) were the citrus strain ICPB 50031 for $X$. fastidiosa subsp. pauca; the grapevine strain ATCC 35879 for $X$. fastidiosa subsp. fastidiosa; and the plum strain ATCC 35879 for $X$. fastidiosa subsp. multiplex. Our MLST of these strains showed that the subsp. pauca ICPB 50031 is ST11 (isolate CVC0145 [19]). This ST corresponds to the genotype frequently found on citrus (type 1 of the reduced MLST scheme used by Almeida et al. [2]), and it is closely related to the other STs seen in subsp. pauca (L. Nunney, X. Yuan, R. E. Bromley, and R. Stouthamer, unpublished data). Similarly, subsp. fastidiosa ATCC 35879 is ST2 (isolate PD0157 [30]) differs by only one base pair across the 7 MLST genes from ST1, by far the most frequent grapevine isolate in the United States (30), and together with ST1, can be considered typical of the subspecies even when we consider the diverse array of genotypes from Central America (19). Thus, in both of these cases, MLST data provide additional support for their choice as subspecific types for subspp. pauca and fastidiosa.

In the case of subsp. multiplex, we have typed more than 110 isolates that can be unambiguously classified as subsp. multiplex; however, two isolates of these showed evidence of intersubspecific recombination at one of the seven MLST loci (L. Nunney, D. Vickerman, R. E. Bromley, S. Russell, J. Hartman, L. Morano, and R. Stouthamer, unpublished data). This evidence is consistent with the observation made from typing subsp. fastidiosa: that homologous recombination has resulted in the transfer of alleles between subspecies $(19,22,30)$. Relevant here is the fact that one of these two recombinant isolates is ATCC 35879 (alias PLS0135), the type for subsp. multiplex. Its sequence type is typical of a broad range of isolates of this subspecies across six of the seven MLST genes, four of which are identical to the alleles found in the sequenced genome (M12); however, at the cys $G$ locus it carries a chimeric allele derived from inter-subspecific recombination (with a $3^{\prime}$ end originating from subsp. fastidiosa) that is atypical of the subspecies (Table 1). Had MLST data been available, it is possible that another subsp. multiplex isolate that showed no such genetic mixing would have been chosen as the type. However, as stated above, we do not suggest that the presence of one recombinant allele in ATCC 35879 should have automatically precluded defining it as the subspecific type, but it would have been one more piece of data relevant to the decision-making process.

\section{CONCLUSIONS}

MLST has proven to be a powerful tool for documenting the genetic variability of bacterial isolates; moreover, it provides an unambiguous "barcode" that identifies any given culture to the level of sequence type. Routine use of MLST would have prevented the two serious problems outlined above, one resulting in the misleading genomic data of the Ann-1 draft sequence, and the other leading to failed experiments since they were based on the belief that Temecula1 bacteria were being used. The possibility of purchasing an incorrect strain from a culture collection is especially disturbing. It is therefore recommended that all isolates 
deposited in culture collections be defined by their sequence type. This would permit most forms of contamination or mislabeling to be identified.

There are many other typing methods available for characterizing bacterial strains, but none possess the advantages of MLST. In the past, numerous serological techniques and genotyping approaches have been employed. In each case, the goal has been to distinguish types based on some form of characteristic fingerprint. Thus, multilocus enzyme electrophoresis differentiates between bacterial strains through the resolution of electromorphs of biochemically metabolic enzymes using gel electrophoresis (5), and pulsed-field gel electrophoresis (PFGE) reveals genetic diversity using restriction enzymes and separation of genomic fragments on an agarose gel. PFGE has high discrimination rate, but has not proven reliable for long-term epidemiological studies (18). Nonsequence-based DNA methods such as amplified fragment length polymorphism, restriction fragment length polymorphisms, randomly amplified polymorphic DNA, and microsatellites (also known as simple sequence repeats) have been used to document nucleotide sequence variation and therefore to discriminate between strains. These methods, especially microsatellites, can be very effective at distinguishing isolates and inferring dispersal patterns at very fine temporal and spatial scales; however, interpreting these data to understand the broader relationships among isolates is problematic (30). At the other extreme, conserved genes, typically, are advantageous in defining relationships among species. The $16 \mathrm{~S}$ rRNA is typical used for this purpose, and is somewhat analogous to the use of COI in the species-level "barcoding" project in animals (28); however, it is usually ineffective in discriminating among closely related taxa (24). In this context, it is worth noting that the barcoding project for land plants has shifted to a two-locus approach (8). Within species, single locus markers, such as $16 \mathrm{~S}-23 \mathrm{~S}$ internal transcriber spacers (ITS), are usually of limited use because any system based on single loci is unlikely to detect recombination events. MLST was specifically designed to detect such events (17).

In the future we can confidently predict the much greater use of whole genome sequencing, largely as a result of decreased cost and improved bioinformatic software. However, in our view, the availability of (roughly) $2.5 \mathrm{Mb}$ of sequence for each Xylella isolate does not alter the utility of filtering the data down to a form of MLST to examine biogeographical and adaptive diversity below the species level. Such filtering is valuable because different regions of the genome represent a heterogeneous mix of both evolutionary time scales and degree of horizontal transmission. As a result, researchers will continue to need a hierarchical system that selects genomic regions with characteristics appropriate to the question being examined. Using whole unfiltered genomic data will provide a measure of the average relatedness among isolates; however, rapidly changing regions will simply cloud the picture for analyses at all but the shortest timescales. We predict that the same levels of analysis currently in use will persist; however, more genetic information is likely to be used at each level. Thus the use of one (16S rDNA) locus to broadly define taxa at the species level and above may be expanded to include other conservative features of the genome. At the other extreme, the analysis of microevolutionary and microgeographic patterns may expand beyond microsatellite loci to include other rapidly evolving features of the genome such as viral inserts, and it is at this level that using whole genomic SNP data is effective. Between these two levels, MLST provides a flexible system that can easily be expanded beyond the traditional seven genes to include a larger group of housekeeping genes. The appropriate number of genes depends primarily upon the clonality of the taxa. In the absence of recombination, even using seven genes is overkill, since alleles are completely correlated; however, as homologous recombination increases, more loci can provide valuable information.
In summary, the number of bacterial species with MLST schemes is growing and once one is developed for a given species genetic typing should be routine. In particular, the organizations maintaining culture collections, such as ATCC, should be actively encouraging the development of MLST. In the near future, MLST protocols should be available for most microbial taxa, so we should soon see MLST signatures routinely associated with isolates used in experimentation. However, it must be emphasized that the goal of MLST is not the individual recognition of isolates. The goal is to achieve effective grouping of isolates at a level that reflects meaningful biological differences. The sequencing of whole genomes will ensure that when necessary isolates can be recognized individually, but this does not undermine the utility of MLST. In the future MLST may most commonly be determined from whole genome data, which will allow it to be more effectively optimized for the intraspecific analysis of adaptation and biogeography.

\section{ACKNOWLEDGMENTS}

We thank R. Almeida and an anonymous reviewer for valuable comments on the manuscript. This work was supported by the United States Department of Agriculture Cooperative State Research, Education, and Extension Service National Research Initiative Plant Biosecurity grant 2007-55605-17834 to L. Nunney and R. Stouthamer.

\section{LITERATURE CITED}

1. Almeida, N. F., Yan, S., Cai, R., Clarke, C. R., Morris, C. E., Schaad, N. W., Schuenzel, E. L., Lacy, G. H., Sun, X., Jones, J. B., Castillo, J. A., Bull, C. T., Leman, S., Guttman, D. S., Setubal, J. C., and Vinatzer, B. A. 2010. PAMDB, A multilocus sequence typing and analysis database and website for plant-associated microbes. Phytopathology 100:208-215.

2. Almeida, R. P. P., Nascimento, F. E., Chau, J., Prado, S. S., Tsai, C. W., Lopes, S. A., and Lopes, J. R. S. 2008. Genetic structure and biology of Xylella fastidiosa causing disease in citrus and coffee in Brazil. Appl. Environ. Microbiol. 74:3690-3701.

3. Bhattacharyya, A., Stilwagen, S., Ivanova, N., D’Souza, M., Bernal, A., Lykidis, A., Kapatral, V., Anderson, I., Larsen, N., Los, T., Reznik, G., Selkov, E., Jr., Walunas, T. L., Feil, H., Feil, W. S., Purcell, A., Lassez, J. L., Hawkins, T. L., Haselkorn, R., Overbeek, R., Predki, P. F., and Kyrpides, N. C. 2002. Whole-genome comparative analysis of three phytopathogenic Xylella fastidiosa strains. Proc. Natl. Acad. Sci. USA 17:12403-12408.

4. Bhattacharyya, A., Stilwagen, S., Reznik, G., Feil, H., Feil, W. S., Anderson, I., Bernal, A., D’Souza, M., Ivanova, N., Kapatral, V., Larsen, N., Los, T., Lykidis, A., Selkov, E., Jr., Walunas, T. L., Purcell, A., Edwards, R. A., Hawkins, T., Haselkorn, R., Overbeek, R., Kyrpides, N. C., and Predki, P. F. 2002. Draft sequencing and comparative genomics of Xylella fastidiosa strains reveal novel biological insights. Genome Res. 12:1556-1563.

5. Boerlin, P., Peter, O., Bretz, A. G., Postic, D., Beranton, G., and Piffaretti, J. C. 1992. Population genetic analysis of Borrelia burgdorferi isolates by multilocus enzyme electrophoresis. Infect. Immun. 60:1677-1683.

6. Buzombo, P., Jaimes, J., Lam, V., Cantrell, K., Harkness, M., McCullough, D., and Morano, L. 2006. An American hybrid vineyard in the Texas Gulf Coast: Analysis within a Pierce's disease hotzone. Am. J. Enol. Vitic. 57:347-355.

7. Castillo, J. A., and Greenberg, J. T. 2007. Evolutionary dynamics of Ralstonia solanacearum. Appl. Environ. Microbiol. 73:1225-1238.

8. CBOL Plant Working Group. 2009. A DNA barcode for land plants. Proc. Natl. Acad. Sci. USA 106:12794-12797.

9. Chen, J., Hartung, J. S., Chang, C. J., and Vidaver, A. K. 2002. An evolutionary perspective of Pierce's disease of grapevine, citrus varigated chlorosis, and mulberry leaf scorch diseases. Curr. Microbiol. 45:423428.

10. Danet, J. L., Bonnet, P., Jarausch, W., Carraro, L., Skoric, D., Labonne, G., and Foissac, X. 2007. Imp and secY, two new markers for MLST (multilocus sequence typing) in the $16 \mathrm{SrX}$ phytoplasma taxonomic group. Bull. Insectol. 60:339-340.

11. de Mello Varani, A., Souza, R. C., Nakaya, H. I., de Lima, W. C., Paula de Almeida, L. G., Kitajima, E. W., Chen, J., Civerolo, E., Vasconcelos, A. T., and Van Sluys, M. A. 2008. Origins of the Xylella fastidiosa prophagelike regions and their impact in genome differentiation. PLoS One 3:e4059-e4573. 
12. Doddapaneni, H., Yao, J., Lin, H., Walker, M. A., and Civerolo, E. L. 2006. Analysis of the genome-wide variations among multiple strains of the plant pathogenic bacterium Xylella fastidiosa. BMC Genom. 7:225.

13. Feng, J., Li, J., Randhawa, P., Bonde, M., and Schaad, N. W. 2009. Evaluation of seed treatments for the eradication of Acidovorax avenae subsp. citrulli from melon and watermelon seeds. Can. J. Plant Pathol. 31:180-185.

14. Hernandez-Martinez, R., de la Cerda, K., Costa, H. S., Cooksey, D. A., and Wong, F. P. 2007. Phylogenetic relationships of Xylella fastidiosa strains isolated from landscape ornamentals in southern California. Phytopathology 97:857-864.

15. Holt, J. G. (ed.) 1994. Bergey's Manual of Determinative Bacteriology. 9th ed. Williams and Wilkins, Baltimore, MD.

16. Maiden, M. C. J. 2006. Multilocus sequence typing of bacteria. Annu. Rev. Microbiol. 60:561-588.

17. Maiden, M. C. J., Bygraves, J. A., Feil, E., Morelli, G., Russell, J. E., Urwin, R., Zhang, Q., Zhou, J., Zurth, K., Caugant, D. A., Feavers, I. M., Achtman, M., and Spratt, B. G. 1998. Multilocus sequence typing: A portable approach to the identification of clones within populations of pathogenic microorganisms. Proc. Natl. Acad. Sci. USA 95:3140-3145.

18. Melles, D. C., Van Leeuwen, W. B., Snijders, S. V., Horst-Kreft, D., Peeters, J. K., Verbrugh, H. A., and Van Belkum, A. 2007. Comparison of multilocus sequence typing (MLST), pulsed- field gel electrophoresis (PFGE), and amplified fragment length polymorphism (AFLP) for genetic typing of Staphylococcus aureus. J. Microbiol. Methods 69:371-375.

19. Nunney, L., Yuan, X., Bromley, R., Hartung, J., Montero-Astua, M., Moreira, L., Ortiz, B., and Stouthamer, R. 2010. Population genomic analysis of a bacterial plant pathogen: Novel insight into the origin of Pierce's disease of grapevine in the US. PloS ONE 2010 5(11):e15488.

20. Purcell, A. H., and Hopkins, D. L. 1996. Fastidious xylem-limited bacterial plant pathogens. Annu. Rev. Phytopathol. 34:131-151.

21. Sarkar, S. F., and Guttman, D. S. 2004. Evolution of the core genome of Pseudomonas syringae, a highly clonal, endemic plant pathogen. Appl. Environ. Microbiol. 70:1999-2012.

22. Scally, M., Schuenzel, E. L., Stouthamer, R., and Nunney, L. 2005. A multilocus sequence type system for the plant pathogen Xylella fastidiosa, and the relative contribution of recombination versus point mutation to clonal diversity. Appl. Environ. Microbiol. 71:8491-8499.

23. Schaad, N. W., Postnikova, E., Lacy, G., Fatmi, M., and Chang, C.-J. 2004. Xylella fastidiosa subspecies: X. fastidiosa subsp. piercei, subsp. nov., $X$. fastidiosa subsp. multiplex subsp. nov., and $X$. fastidiosa subsp. pauca subsp. nov. Syst. Appl. Microbiol. 27:290-300.

24. Schleifer, K. H. 2009. Classification of bacteria and archaea: Past, present and future. Syst. Appl. Microbiol. 32:533-542.

25. Schreiber, H. L., Koirala, M., Lara, A., Ojeda, M., Dowd, S. E., Bextine, B., and Morano, L. 2010. Unraveling the first Xylella fastidiosa Subsp. fastidiosa genome from Texas. Southwest. Entomol. 35:479-483.

26. Schuenzel, E. L., Scally, M., Stouthamer, R., and Nunney, L. 2005. A multigene phylogenetic study of clonal diversity and divergence in North American strains of the plant pathogen Xylella fastidiosa. Appl. Environ. Microbiol. 71:3832-3839.

27. Van Sluys, M. A., de Oliveira, M. C., Monteiro-Vitorello, C. B., Miyaki, C. Y., Furlan, L. R., Camargo, L. E., da Silva, A. C., Moon, D. H., Takita, M. A., Lemos, E. G., Machado, M. A., Ferro, M. I., da Silva, F. R., Goldman, M. H., Goldman, G. H., Lemos, M. V., El-Dorry, H., Tsai, S. M., Carrer, H., Carraro, D. M., de Oliveira, R. C., Nunes, L. R., Siqueira, W. J., Coutinho, L. L., Kimura, E. T., Ferro, E. S., Harakava, R., Kuramae, E. E., Marino, C. L., Giglioti, E., Abreu, I. L., Alves, L. M., do Amaral, A. M., Baia, G. S., Blanco, S. R., Brito, M. S., Cannavan, F. S., Celestino, A. V., da Cunha, A. F., Fenille, R. C., Ferro, J. A., Formighieri, E. F., Kishi, L. T., Leoni, S. G., Oliveira, A. R., Rosa, V. E., Jr., Sassaki, F. T., Sena, J. A., de Souza, A. A., Truffi, D., Tsukumo, F., Yanai, G. M., Zaros, L. G., Civerolo, E. L., Simpson, A. J., Almeida, N. F., Jr., Setubal, J. C., and Kitajima, J. P. 2003. Comparative analyses of the complete genome sequences of Pierce's disease and citrus variegated chlorosis strains of Xylella fastidiosa. J. Bacteriol. 185:1018-1026.

28. Vences, M., Thomas, M., van der Meijden, A., Chiari, Y., and Vieites, D. R. 2005. Comparative performance of the $16 \mathrm{~S}$ rRNA gene in DNA barcoding of amphibians. Frontiers Zool. 2:5.

29. Young, J. M., Park, D. C., Shearman, H. M., and Fargier, E. 2008. A multilocus sequence analysis of the genus Xanthomonas. Syst. Appl. Microbiol. 31:366-377.

30. Yuan, X., Morano, L., Bromley, R., Spring-Pearson, S., Stouthamer, R., and Nunney, L. 2010. Multilocus sequence typing of Xylella fastidiosa causing Pierce's disease and oleander leaf scorch in the United States. Phytopathology 100:601-611.

31. Zhang, S., Flores-Cruz, Z., Kumar, D., Chakrabarty, P., Hopkins, D. L., and Gabriel, D. W. 2011. The Xylella fastidiosa biocontrol strain EB92-1 genome is very similar and syntenic to Pierce's disease strains. J. Bacteriol. 193:5576-5577. 